\title{
MODEL CAR TRANSPORT SYSTEM - MODERN ITS EDUCATION TOOL
}

\author{
Karel Bouchner*, Alina Mashko \\ Department of vehicles, CTU in Prague, Horská 3, Praha 2, 120 00, Czech Republic \\ * corresponding author: bouchkar@fd.cvut.cz
}

ABstRaCT. The model car transport system is a laboratory intended for a practical development in the area of the motor traffic. It is also an important education tool for students' hands-on training, enabling students to test the results of their own studies.

The main part of the model car transportation network is a model in a ratio 1:87 (HO), based on component units of FALLER Car system, e.g. cars, traffic lights, carriage way, parking spaces, stop sections, branch-off junctions, sensors and control sections. The model enables to simulate real traffic situations. It includes a motor traffic in a city, in a small village, on a carriageway between a city and a village including a railway crossing. The traffic infrastructure includes different kinds of intersections, such as T-junctions, a classic four-way crossroad and four-way traffic circle, with and without traffic lights control. Another important part of the model is a segment of a highway which includes an elevated crossing with highway approaches and exits.

KEYwORDS: model car transportation system (model), motor traffic, Intelligent Transport System (ITS), Smart City.

\section{INTRODUCTION}

With a constant growth of people mobility, expansion of cities infrastructure, increase in traffic flow, traffic density in the cities, the efficient traffic management systems are rather crucial. Telematic systems are being used for traffic monitoring and control. The road traffic is affected by a number of parameters such as weather conditions, infrastructure, human behavior, technical state of a vehicle etc. Telematic systems are used in city planning, transport management, parking solutions, operation of logistics and municipal services, organization of urban space, implementation of sustainable energy sources. It can as well as be comprised under an umbrella term, the smart city initiative, and it is approached from the view of different disciplines including technical, economic, humanitarian, legal etc. 1 .

Traffic modeling is important in the process of traffic systems implementation. The preliminary system simulation and testing in laboratory conditions with implementation of real traffic data is safe and provides feasible results that can be used for timely corrections and improvement in traffic management schemes. There are many advantages of performing traffic studies in safe laboratory conditions. These include possibility of simulating the enforcement of services work in emergency situations, simulating dangerous human behavior in traffic with a high density, dangerous road sections or on high-speed roads, planning safer routes for dangerous goods transportation, efficient city traffic planning including city municipal transport, parking areas, better overview of city safety in general etc. Rather crucial for smart city technologies is testing newly developed telematic systems on real traffic data which can be realized within the suggested model [2, 3]. The smart city solutions are to take into account the existing city architecture while dealing with efficient energy flows [4.

The mathematical (or general) models of such complex systems provided with the use of tools of virtual reality to the users are nowadays very popular and widely applied. However, the real interpretation of the models is still for many people straightforward for understanding and working with. The real models are not only convenient for demonstration and illustration purposes, but they are also especially convenient for education and training.

The model car transport system described herein presents a laboratory with a physical model of infrastructure and is intended for research and analysis of road traffic monitoring and management and is realized at Department of Vehicle Technology at Faculty of Transportation Sciences at CTU in Prague.

A similar project has been realized for rail traffic model within the Laboratory of Transport Technology [5] and is running at Department of Transport Telematics of CTU, Prague.

\section{SYSTEM OVERVIEW}

The basis of the model car transportation network is a model in a ratio 1:87 (HO), based on component units of FALLER Car System[ [], e.g. vehicles, traffic lights, carriageway, parking spaces, stop sections, branch-off junctions, sensors and control sections (see Figure [1] 6 ).

The FALLER Car System was initially designed to complement railway models. In our case it is used the other way around. The fundamental car model is 

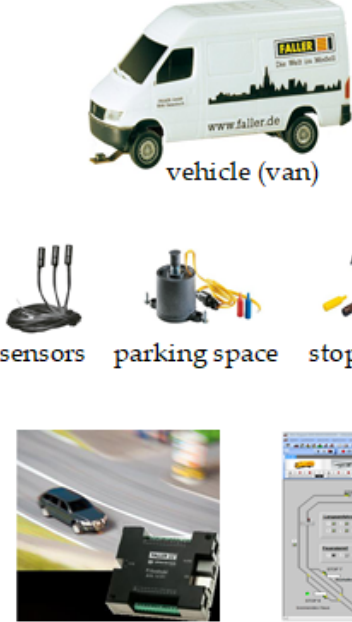

HW control section
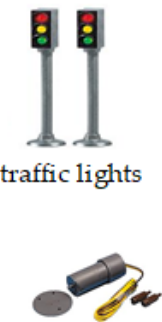

branch-off junction
Figure 1. Some components of the model. Source: 6].
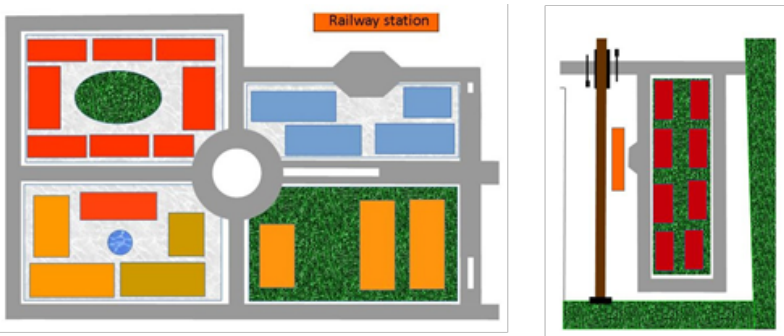

Figure 2. City (left) and village (right) infrastructure.

supplemented with a small railway that among other things includes two railway stations and a railway crossing. It enables simulation of real traffic situations on intra- and extravilan communications with a level crossing with a rail road and a section of highway (see Figures 2 through 5 for reference). See the general schematic representation of the whole model on Figure 6.

\subsection{TECHNICAL DESCRIPTION OF THE MODEL}

Road in the model is realized with the help of wooden plates. The technology that controls vehicles' lateral movement is allocated within the road surface (wire rail) and under the surface.

Model vehicles are equipped with an electric motor, a steering apparatus, a rechargeable battery, an on/off switch on the bottom of the car to start it and a reed sensor that responds to magnet effect. Permanent magnet tip is attached in a flexible way under the road so that an approaching vehicle with steering mechanism in front responds to wire magnetism which is keeping vehicles on track.

\subsubsection{PhysicAl LAYER OF THE MODEL INFRASTRUCTURE}

Physical part of the model is represented by the road that is built up with the help of wooden plate elements

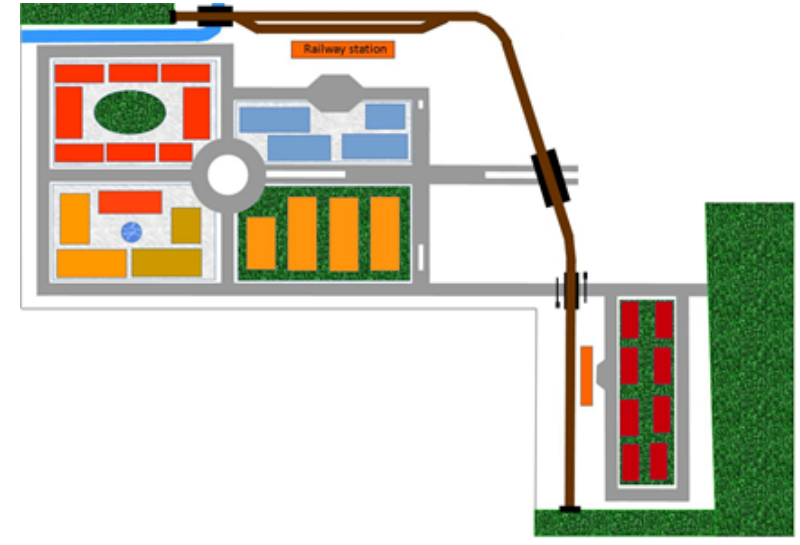

FiguRE 3. Intravilan connection.

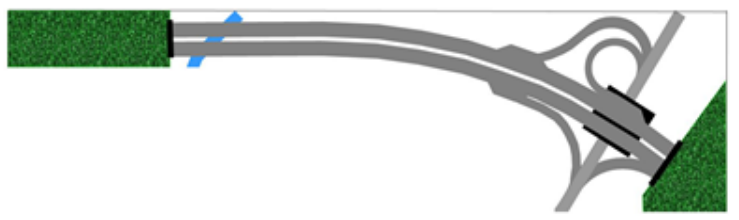

Figure 4. Highway section with a trumpet-type interchange.

fixed on foam plastic pieces of various constructions for modeling of different terrain levels. A wire rail is embedded into the wooden road along its length. Control sections are placed under the road (see Figures 7 through 9 for physical layer elements for reference).

Sensors are used for activation of functional elements, for example stop sections, parking spaces and branch-off junctions. They contain reed contact. Sensors embedded in the road are activated by magnets on the vehicles when the vehicle goes over the sensor. The sensor gives precise feedback on the traffic control. This signal activates the control of a functional element.

\subsection{TRAFFIC CONTROL}

- Traffic node control - intersection

The stop section (see Figure 10) is needed to initiate vehicle full stop at road junctions (intersections and level intersections), bus stops, parking slots etc. It consists of an electromagnet embedded in the roadway. With power, its magnetic field will switch off the vehicle's motor power via the reed sensor.

For example, stop sections together with traffic lights and HW control section can control traffic on a classic four-way crossroad in a completely automated way (see Figure 11.

- Traffic node control - navigation and routing The branch-off junction (see Figure 12) is used for turning of vehicles to the right or left. When activated, the magnetic field of the branch-off junction diverts a vehicle onto a second, branching contact wire. This is done through the magnet on the vehicle's steering slider. 


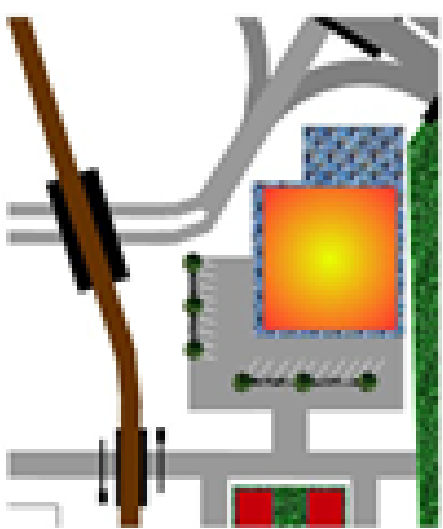

FiguRE 5. Supermarket with parking.

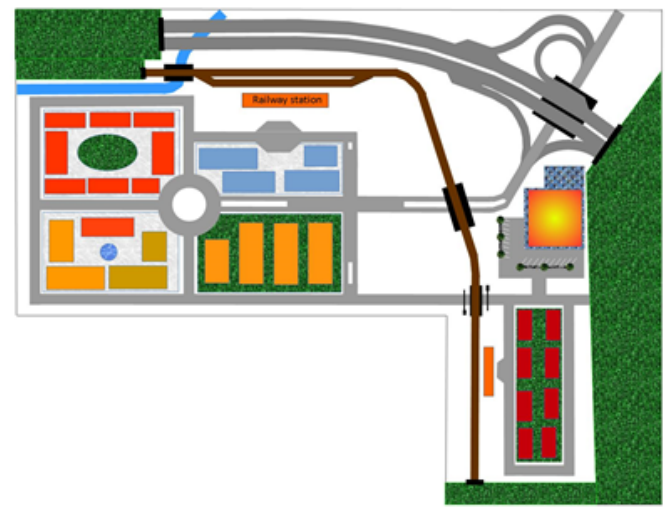

FiguRE 6. General schematic representation of traffic real model.

\section{- Parking control}

Permanent magnet is also applied in case of longer stops such as parking (see Figure 13). When the parking space is activated, an integrated electric coil briefly interferes with this magnetic field. This closes the reed sensor in the vehicle and supplies power to the motor. The vehicle starts moving.

The traffic infrastructure includes different types of intersections including T-junctions, a classic fourway crossroad with traffic lights and a four-way traffic circle, bus stops etc.

An important part of the model is a segment of a highway which includes an elevated crossing with highway entries and exits. The highway has two lanes in each direction. Such an arrangement corresponds to common real construction of highways (according to standard [7, except for a few parts where accommodation was needed due to space constrains). The two-lane arrangement enables to simulate real traffic situations, e.g. when one vehicle enters the highway and the second one is approaching to the highway at the same time, or during overtaking of vehicles on the

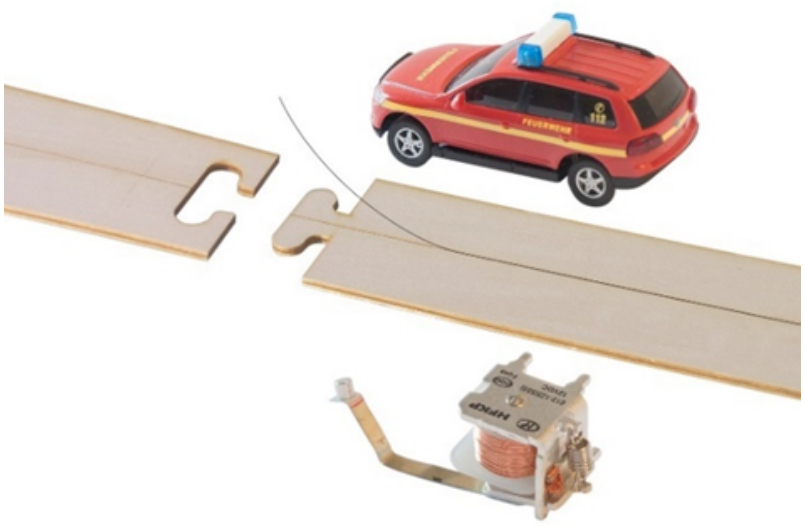

FiguRE 7. Road with metal wire, with control element.
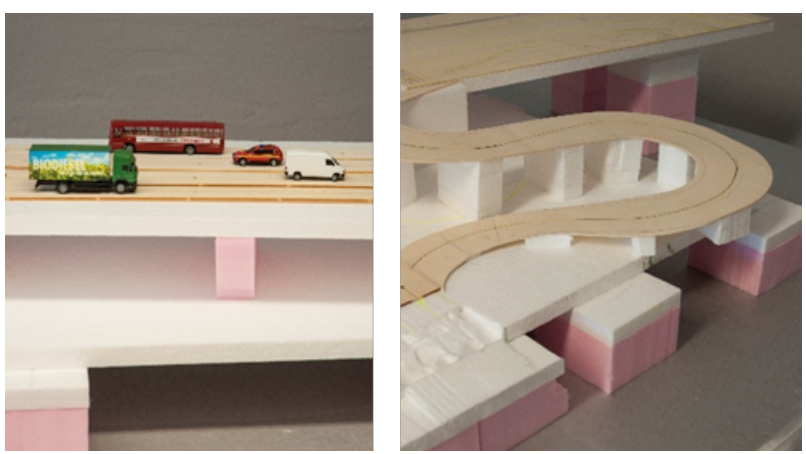

FIGURE 8. Physical part of road construction in different sections (left - four-way highway, right - elevated intersection) and model vehicles.

highway.

A disadvantage of the technology is that a movement of model vehicles does not fully correspond to a behavior of real vehicles. Model vehicles move by a constant speed. The speed depends only on a status of a rechargeable battery. When the battery is fully charged the speed is the highest. During its discharging, the speed of model vehicle decreases. So far, model vehicles are neither able to start and stop smoothly, nor to vary their speed. In addition, now, their speed does not correspond to a type of real vehicles.

\subsection{MODEL OPERATION AND CONTROL}

There are three different ways to control the whole model:

\section{- Manual control}

An operator activates the control of functional elements manually, using push buttons and switches. Model vehicles move according to the operator's immediate actions.

\section{- Preset automatic control}

The functional elements are controlled by associated control sections. The operation of the control sections can be either fully automatic, depending only on their initial setting, or depending on their initial 


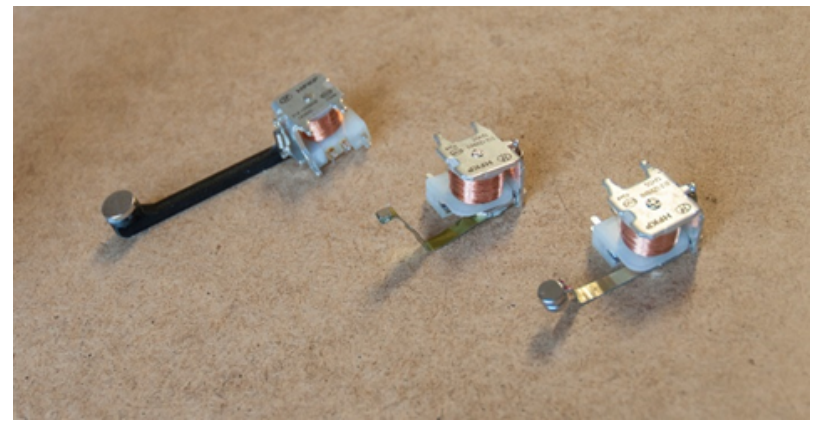

Figure 9. Examples of three types of control sections (from left to right): parking space, stop section and branch-off junction - an alternative to Faller elements.

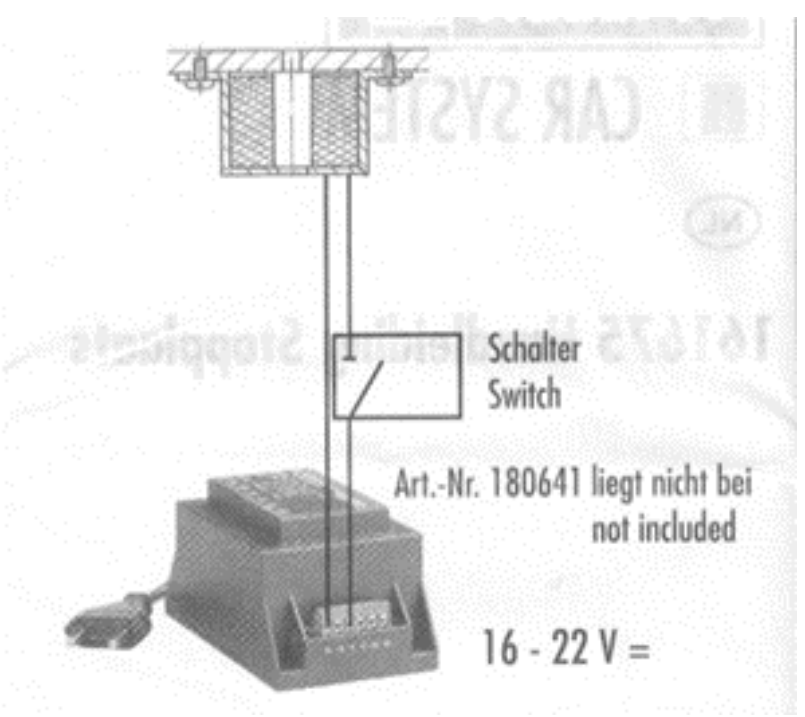

Figure 10. Stop section. Source: [6].

setting in combination with signals from the associated sensors. Model vehicles move according to their immediate status of functional elements controlled by the corresponding control section. Operation of individual control sections is not synchronized.

\section{- Program control}

The functional elements are controlled by an associated PC-standard module and expansion modules. The PC-standard module is connected to a PC with an appropriate SW application and interconnected with expansion modules. Also sensors are connected to the modules. An operator creates on the $\mathrm{PC}$ programs of different traffic situations for the whole model, using the SW application. The SW application also utilizes signals from sensors for its activity. Modules operate according to the running program. Model vehicles move according to their immediate status of functional elements controlled via corresponding modules by the running program.

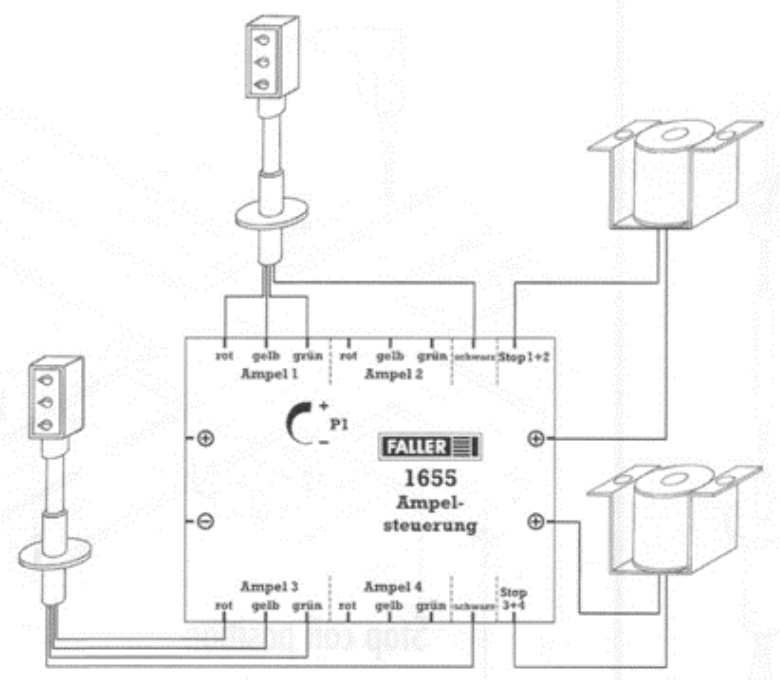

FiguRE 11. Example of intersection control. Source: 6].

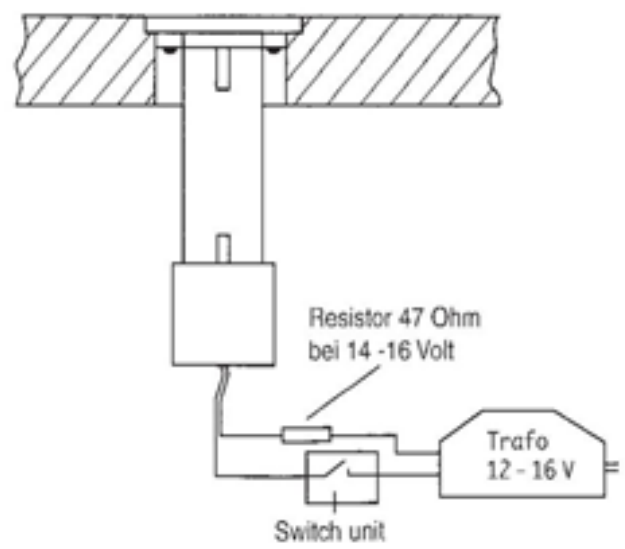

Figure 12. Branch-off junction. Source: 6].

\section{Further PERSPECTIVE}

The current model shall be used as the basis platform for future smart systems implementation, programming based on real traffic data, or for simulation of real traffic and driver behavior. It brings several challenges for the development of software applications for intelligent transport systems, implementations of more traffic data collectors such as a camera or road section detectors and other traffic surveillance and control systems [8]. The system may serve for students' training in a wide range of disciplines applied in transport studies and research, namely, traffic management and control, city planning and infrastructure design, software development, driver behavior and humanmachine interaction just to name a few. The current project has a goal to design a fully automatically operated system with simulation of vehicle-to-vehicle $(\mathrm{v} 2 \mathrm{v})$, infrastructure-to-vehicle (i2v or v2i) commu- 


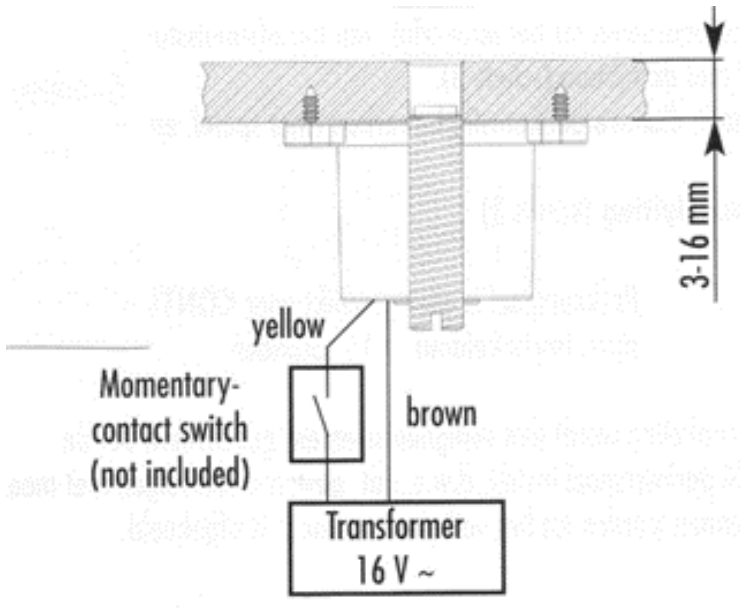

Figure 13. Parking space. Source: 6].

nication in a way so that fully autonomous vehicles could drive in real conditions. The video-based data from the cameras that will be installed in the system will provide the traffic information for decisions to be taken by robot drivers of individual vehicles. The cameras are to be installed in the control sections and on the vehicles for strategic route planning as well as immediate reaction to the traffic in front, correspondingly. The front cameras can also be used for manual vehicle control with remote driver. Thus, it is planned to simulate possible future scenarios of vehicle operation in smart cities 9 .

\section{Conclusion}

The Model Car Transport System is one of important tools, assisting students of Faculty of Transportation Science in their study. It facilitates understanding of matters of the Intelligent Transport System and the Smart City. Finally, it enables a comprehensive application of student theoretical knowledge in a wide range of transportation theory topics, in informatics, electronics, control theory. It is an appropriate tool for software and model hardware testing of various ITS applications and tools applicable in Smart City projects.

\section{REFERENCES}

[1] M. Lom, O. Přibyl, M. Svítek. Industry 4.0 as a Part of Smart Cities. Conference Paper. Smart Cities Symposium Prague 2016. DOI: 10.1109/SCSP.2016.7501015.

[2] L. Galán-García, G. Aguilera-Venegas, P. Rodrígues-Cielos. An accelerated-time simulation for traffic flow in a smart city. Journal of Computational and Applied Mathematics. Volume 270, November 2014, Pages 557-563.

[3] Z. Li, M. Shahidehpour. Deployment of cybersecurity for managing traffic efficiency and safety in smart cities. The Electricity Journal. Volume 30, Issue 4, May 2017, Pages 52-61.
[4] C. Navarro, M. Rca-Riu, S. Furió, M. Estrada. Designing New Models for Energy Efficiency in Urban Freight Transport for Smart Cities and its Application to the Spanish Case. Transportation Research Procedia. Volume 12, 2016, Pages 314-324.

[5] Laboratory of transport technics. Czech Technical University in Prague, Faculty of Transportation Sciences, Department of Transport Telematics (16120), Konviktská 20, Prague 1, 11000 Czech Republic, http://dsfd.fd.cvut.cz, 10.2.2017.

[6] FALLER GmbH, Gütenbach / Schwarzwald. Amtsgericht Freiburg HRB610917, http://www.faller.de, 7.10.2016.

[7] ČSN 736101 Projektování silnic a dálnic. Praha: Český normalizační institut, 2004.

[8] M. A.-P.-Taylor. Intelligent transport systems. University of South Australia, Adelaide, http://www.emeraldinsight.com/doi/abs/10.1108/ 9781615832460-031, 10.2.2017.

[9] Conceptualizing Smart City with Dimensions of Technology, People, and Institutions. Taewoo Nam \& Theresa A. Pardo, Center for Technology in Government, University at Albany, State University of New York, U.S., https : //www.ctg.albany.edu/publications/journals/dgo_ 2011_smartcity/dgo_2011_smartcity.pdf 10.2.2017. 